\title{
Norsk arbeidsmedisinsk epidemiologi: Hvor står vi? Hvor går vi?
}

\author{
Helge Kjuus \\ Statens arbeidsmiljøinstitutt, P.b. 8149 Dep., 0033 Oslo \\ Telefon: 23195370 Telefax: $23195205 \quad$ E-post: Helge.Kjuus@stami.no
}

\begin{abstract}
SAMMENDRAG
Arbeidslivet frembyr populasjoner med gunstige eksponeringskontraster, som kan være et attraktivt utgangspunkt for årsakssøkende epidemiologi. Denne artikkel gir eksempler på innholdsmessig og metodemessig praksis innenfor det arbeidsmedisinske epidemiologiske fagområdet i Norge de siste decennier, og peker på en del utfordringer for fremtidig virksomhet innenfor den arbeidsmedisinske epidemiologien. Økende gradienter i livsstil og helse, kompliserte årsaksnettverk, multikomponent, lavgradig eksponering og bruk av nye effektmarkører vil være noen av fremtidens utfordringer.
\end{abstract}

\section{Kjuus H. Occupational epidemiology in Norway. Status and future challenges. Nor J Epidemiol 1999; 9 (1): 5-11.}

\section{ENGLISH SUMMARY}

The traditional exposure contrasts found in working populations represent an attractive starting point for epidemiological studies. This paper gives examples of past and current practice in the field of occupational epidemiology in Norway, and discuss some challenges for future epidemiologic studies. Increasing gradients in lifestyle and health, complicated causal webs, low exposure to a multitude of factors, and use of new biomarkers for effect represent some of these challenges.

\section{INNLEDNING}

Arbeidslivet er på mange måter et spesielt egnet utgangspunkt for epidemiologiske studier. Store grupper av arbeidere med høy eksponering for helseskadelige agens, ansatt i bedrifter eller bransjer med komplette registre over eksponerings- og ansettelsesforhold, sammenholdt med informasjon om sykelighet synes å være et gunstig utgangspunkt for gruppebaserte, observasjonelle studier. Mange årsaksfaktorer til miljøbetinget sykdom ble først avdekket gjennom epidemiologiske studier blant eksponerte arbeidere (1).

\section{KORT TILBAKEBLIKK}

Den første egentlige epidemiologiske undersøkelsen innenfor det arbeidsmedisinske fagområdet ble publisert av Sir Percivall Pott, som i 1775 rapporterte en dramatisk overhyppighet av skrotal kanser blant feiere i London. At årsaken var hudeksponering for karsinogene polyaromatiske hydrokarboner ble først klart mange år senere. Dette er dermed også et godt eksempel på at en epidemiolog kan ha antakelser om kausale sammenhenger, uten at den biologiske mekanisme er kjent. De første arbeidsmedisinske epidemiologiske studiene i mer moderne forstand ble publisert i begynnelsen av 1950-årene. Da kom de banebrytende arbeidene til Sir Richard Doll, som fant en klar overhyppighet av lungekreft blant gassverksarbeidere (2), og til Case og medarbeidere, som påviste sammenheng mellom blærekreft og eksponering for aromatiske aminer i fargestoffindustrien (3).

I Norge kan vi se tilløp til epidemiologisk, systematisk tenkning tilbake til 1930-tallet. Det finnes en rekke eksempler på årvåkne bedriftsleger som på basis av clusterobservasjoner i homogent eksponerte grupper gjennomførte kvalitativt gode studier etter datidens krav (4). Distrikslege Elstads observasjon av en påfallende overdødelighet av pneumonier i Sauda med mulig relasjon til manganeksponering initierte en aktiv forskning rundt «mangan-pneumonien» (5). En annen av pionerene i denne tiden var nylig avdøde Eyvind Thiis-Evensen, som i sine undersøkelser i perioden 1933-40 påviste at omkring $40 \%$ av alle ansatte i norsk porselensindustri hadde silikose (6).

Det er til sammenlikning tankevekkende at mer systematisk epidemiologisk kartlegging av asbestbetingete sykdommer ikke kom skikkelig i gang før på 1970-tallet, over 30 år etter at Åge Wolff så glimrende beskrev de første tilfelle av asbestose i Norge blant an- 
satte ved Rjukan Salpeterfabrikk (7). I løpet av 1970og 80-årene har imidlertid asbestsykdommer, og ikke minst asbestbetinget kreft vært en av de mest studerte tilstander innenfor arbeidsmedisinsk epidemiologi. Haakon Natvig og Eyvind Thiis-Evensen sen. utarbeidet i 1983 en nærmest komplett oversikt over publisert norsk litteratur om arbeidsmiljø og helse, med over 1200 referanser (4). Totalt sett er det imponerende å registrere hvor omfattende problemstillinger både med hensyn til eksponeringsforhold og effektmål som har vært benyttet $\mathrm{i}$ de tallrike undersøkelser av epidemiologisk karakter med utgangspunkt i yrkeseksponerte grupper i Norge i løpet av de siste 50 år.

\section{HVOR STÅR VI?}

Norsk arbeidsmedisinsk epidemiologi har vært i betydelig vekst og utvikling de siste 10-20 år, både temamessig og metodemessig. Denne gjennomgang har ikke til hensikt å presentere et representativt utvalg av de sentrale undersøkelser innenfor det arbeidsmedisinske fagfelt i løpet av de siste decennier. Utgangspunktet er heller å komme med noen eksempler på metodemessige og innholdsmessige forhold som har vært av betydning for utformingen av dette fagområdet de senere år og knytte enkelte refleksjoner til disse. Videre å gi enkelte stikkordsmessige betraktninger for fremtidige utfordringer innenfor den arbeidsmedisinske epidemiologien.

\section{Hvilke arbeidsrelaterte sykdommer har vart studert?}

Metodemessig solide, vel gjennomførte kreftinsidens studier, basert på historiske kohorter koblet med data fra et kvalitetstungt Kreftregister har på mange måter vært flaggskipet i norsk arbeidsmedisinsk epidemiologi. Med de siste decenniers fokus på miljøbetinget kreft, er det ikke overraskende at yrke-kreft undersøkelser har vært dominerende. Asbest har vært den betydeligste eksponeringsfaktoren i denne sammenheng $(8,9)$. Når opp til $1 / 5$ av all lungekreft hos norske menn har vært relatert til asbesteksponering (10), utgjør dette ikke bare et arbeidsmedisinsk problem, men også et folkehelseproblem.

Bekymring for helseeffekter pga. luftforurensninger i arbeidsmiljøet har ført til at lunger og luftveier har vært sentrale effektorgan i studier i en rekke bransjer og industrier. Undersøkelsene av «hallastma» og lungefunksjon blant ansatte i aluminiumsindustrien fremstår som de mest omfattende på dette området $(11,12)$.

Nevrotoksiske effekter har også vært studert, fortrinnsvis knyttet til metalleksponering. Norge var for øvrig sammen med Sverige og Danmark blant de land som relativt rask anerkjente en mulig sammenheng mellom løsemiddeleksponering og kronisk, toksisk encephalopati. På 80-tallet og begynnelsen av 90-tallet ble det utredet et betydelig antall pasienter med mulig løsemiddelskade, og denne pasientkategori er fortsatt $i$ flertall ved de arbeidsmedisinske klinikker i Norge i dag. Det er overraskende at en ikke i større grad benyttet anledningen til mer systematisk epidemiologisk tilnærming i Norge.

I løpet av de siste 10 år har sammenheng mellom arbeidsmiljø og reproduksjonsskader i økende grad blitt gjenstand for epidemiologiske undersøkelser. De fleste slike undersøkelser har tatt utgangspunkt i Medisinsk fødselsregister, der f.eks. misdannelser er blitt koblet mot andre registre med informasjon om yrke/arbeidsmiljø $(13,14)$.

Bortsett fra en del yrke-død-studier basert på yrkestitler ved folke- og boligtellingene i 1960 og 1970, har dødelighet av andre årsaker enn kreft i liten grad blitt studert i relasjon til arbeidsmiljø. Hjerte/kar sykdommer har vært bort i mot helt fraværende i den arbeidsmedisinske epidemiologien i Norge. Dette henger nok sammen med at tilgjengeligheten på slike effektdata har vært mindre. Det er derfor gledelig at forholdene nå legges bedre til rette i Statistisk Sentralbyrå for gjennomføring av studier basert på årsaksspesifikk dødelighet.

Det har det siste tiår vært betydelig fokus på forekomsten av arbeidsrelaterte muskel-skjelettplager i Norge. Epidemiologiske undersøkelser har det imidlertid vært lite av, noe som nok har sammenheng med de betydelige problemer en har både med å karakterisere eksponering og effektmål i slike undersøkelser (15).

\section{Registerkoplinger - kilde til ny kunnskap eller malpraksis?}

Økende tilgjengelighet av elektronisk, registerbasert informasjon både om eksponering og sykdom har vært et naturlig utgangspunkt for en rekke studier av sammenheng mellom arbeidsmiljø og helse. Slike undersøkelser muliggjør studiet av sjeldne sykdommer, og kan omfatte store befolkningsgrupper. Designmessig har slike studier imidlertid klare begrensninger. Informasjon om f.eks. yrkestittel eller bransje blir oftest innhentet for administrative formål, og ikke forskningsmessige. Selv om den ledsagende misklassifikasjonen i utgangspunktet antas å være ikke-systematisk, med utvanning av en eventuell assosiasjon som resultat, kan slike non-positive undersøkelser innenfor det arbeidsmedisinske fagfelt lett mistolkes som negative. Mange i fagmiljøet har derfor vært kritiske til registerkoblinger.

Brukt med innsikt, biologisk teft og kreativitet kan imidlertid kobling av registerdata være et spennende utgangspunkt for videre hypotesedannelse. Et eksempel er en nylig gjennomført registerstudie som gjennom kobling av en rekke registre påviste en overhyppighet av senabort hos hustruer til kornbønder, spesielt i år hvor klimaforholdene favoriserte oppvekst av sopp og mykotoksindannelse (14). I tillegg til kobling av data fra Kreftregister, Medisinsk fødselsregister, opplysninger fra landbrukstellingene og det sentrale personregister, ble det benyttet ytterligere 
kobling med lokale, tidsspesifikke meteorologiske data. Denne undersøkelsen følges nå opp med feltundersøkelser for kartlegging av mykotoksiner og andre organiske komponenter i kornstøv, samt case controlundersøkelser med detaljert eksponeringskarakterisering. Designmessig er dette et godt eksempel på registerepidemiologiens muligheter, både alene og enda mer i kombinasjon med andre typer tilnærming.

\section{“Mot normalt" - sammenlikning med hvem?}

En annen hovedutfordring $\mathrm{i}$ arbeidsmedisinske studier har vært valg av referansepopulasjon. Ikke minst $i$ studier av kreft og dødelighet har praksis ofte vært å benytte nasjonale rater, evt. regionale rater som sammenlikningsgrunnlag. Som kjent er den arbeidende del av befolkningen helsemessig selektert, både ved ansettelse og under aktivt arbeid, et fenomen som har blitt kalt «healthy worker effect». Selv om dette fenomen i større grad gjelder dødelighet enn kreft, har dette metodeproblem vært betydelig, også i en rekke, større epidemiologiske undersøkelser som er gjennomført $i$ norsk industri. Ikke minst tolkningen av en mulig overhyppighet av arbeidsbetinget lungekreft har vært problematisk, pga. høyere røykeprevalens blant industriarbeidere enn i befolkningen for øvrig. Inkomplette røykedata i disse historiske kohortene med ledsagende ukontrollert confounding av ukjent størrelse har ofte ført til uklare, vanskelig tolkbare resultater. Teknikker for «justering» for slik ukontrollert confounding har vært utviklet, basert på modeller for antatt confounderforekomst og assosiasjonens styrke, men tolkningene av slike resultater er problematiske.

Ut fra kriteriet om at referansepopulasjonen skal være lik indekspopulasjonen, bortsett fra den studerte eksponering, er det designmessig svært utilfredsstillende å velge hele populasjonen som sammenlikningsgruppe. Eller for å sitere Miettinen: «a manifestation of the benightedness that still shrouds epidemiologic research modeled after its traditional paradigms» (16). Den økende tendensen til at negativ livsstil og helseadferd i større grad gjelder grupper med potensielt mer helseskadelig arbeidsmiljø gjør dette problemet metodemessig økende. Den eneste plausible grunn for å fortsette denne malpraksis (som de fleste av oss har benyttet oss av), er at dødelighetsdata og kreftinsidensdata for hele befolkningen er robuste og lett tilgjengelig. Bedre utnyttelse av kohortinterne eksponeringskontraster kan være et alternativ, dersom kohorten er stor nok (17). Ansatte i samme bransje benyttes også i økende grad (tunnelarbeidere uten Rhoca-Gil eksponering, smelteverksarbeidere uten manganeksponering etc.)

\section{Case control undersokelser - de mange eksponeringers mulighet}

Arbeidere er gjennom et langt liv utsatt for mange forskjellige eksponeringsfaktorer, som vanskelig kan ivaretas gjennom en kohorttilnærming. Arbeids- medisinen har i relativt beskjeden grad benyttet seg av de fordeler som ligger i en case control design. En grunn til dette, bortsett fra begrenset kompetanse blant arbeidsmedisinere for 10-20 år tilbake, kan ha vært manglende tilgang på pasienter/diagnoseregistre. Basert på en mulig cluster av parkinsonisme blant befolkningen i Sauda, som en kunne mistenke var manganrelatert, ble det i sin tid vurdert å starte en case control undersøkelse i området. Undersøkelsen strandet på manglende tilgang på pålitelig, eksponeringsuavhengig diagnosesetting og lavt antall pasienter. Recall bias kan også være en spesiell utfordring innenfor arbeidsmedisinen, der pasienter kan fristes til å overdrive sin eksponering pga. mulige økonomiske fordeler av en arbeidsbetinget diagnose.

Et attraktivt designvalg som foreløpig bare har vært benyttet $\mathrm{i}$ begrenset omfang i norske arbeidsmedisinske studier, er kohort-interne (eller «nested») case control undersøkelser. Slike undersøkelser, der alle innen en definert kohort med en gitt sykdom og et utvalg av de øvrige i kohorten kartlegges i detalj med hensyn til alle relevante, tilgjengelige eksponeringsforhold, gir en høy kostnadseffektivitet sammenliknet med de tradisjonelle kohortundersøkelsene.

\section{Skal vi fortsatt leve i nuet?}

Ute i bedrifter, og blant bedriftshelsetjenester har naturlig nok tverrsnittsnitttsundersøkelsene vært et nærliggende designvalg. Brukt med innsikt og forsiktighet kan slike undersøkelser gi nyttig informasjon, og være et godt utgangspunkt for videre studier med mer krevende design. I verste fall kan slike tverrsnittsundersøkelser bidra til desinformasjon, f.eks. i ekstremvarianter med betydelig «healthy worker effect». Hovedproblemet i slike tverrsnittsundersøkelser er at en i tillegg til seleksjon inn og under arbeid, også får en seleksjon ut av arbeid. Påvisning av overhyppighet av f.eks. lungesykdommer blant ansatte i de minst forurensete avdelinger $\mathrm{i}$ en bedrift pga. omplassering av personer med lungeplager til ikke eksponert arbeid, kan være det paradoksale resultat i slike bedrifts- og bransjebaserte tverrsnittsundersøkelser. Non-positive undersøkelser har også vært feiltolket som negative, basert på de samme forhold.

\section{Hvorfor har vi ikke vaert mer framsynte?}

Rene prospektive, arbeidsmedisinske studier som begynner med friske personer ved start av en eksponeringskarriere, og som så følges over tid for observasjon av sykdom, har så vidt vites knapt vært gjennomført i Norge. Et slikt design ble forsøkt benyttet i en pågående oppfølgingsstudie blant dykkere, som initialt ble lungefysiologisk, audiometrisk og nevropsykologisk undersøkt ved opptak som elever på en dykkerskole, og som til nå er reundersøkt etter 3 år, med planlagt reundersøkelse etter 6 års observasjon (18). Men selv ikke i denne undersøkelsen var det mulig å starte med helt ueksponerte, da de fleste dykkerskoleelever hadde 
drevet med dykking på forhånd. Slik prosjektaktivitet forutsetter en viss kontinuitet over tid, noe som det til dels legges lite til rette for i norske forskningsmiljøer. Fokus på antall publikasjoner og 3-års begrensninger på stipendiatmidler fra forskningsråd og andre finansieringskilder kan nok ha stimulert til «kjappere» designvalg basert på tverrsnittsundersøkelser og eventuelt historiske kohorter.

\section{Når skal vi begynne å forebygge?}

Forebyggelse av arbeidsrelatert sykdom er et sentralt anliggende innen arbeidsmedisinen. Det er derfor påfallende at gruppebaserte intervensjonsstudier, der effekt av tiltak måles før og etter en systematisk intervensjon bare i liten grad har vært benyttet som metode til å demonstrere eventuell effekt av forebyggende tiltak. Et hederlig unntak er bedriftslege Arne Aarås sine mangeårige systematiske intervensjoner vedrørende ergonomiske forhold og muskelskjelettplager blant ansatte ved Alcatel STK som internasjonalt har vakt stor anerkjennelse (19). Norges Forskningsråds program «Helse i arbeidslivet» ønsket å prioritere intervensjonsundersøkelser i perioden 1994-98, da mest med fokus på organisatoriske arbeidsmiljøforhold. Hvorvidt den relativt betydelige prosjektaktiviteten har svart til forventningene gjenstår å se, da kun et fåtall av de aktuelle prosjekter i programmet er avsluttet (20).

\section{Behov for bedre eksponeringsopplysninger}

Tradisjonelt har det vært et betydelig misforhold i kvaliteten mellom de to hovedvariablene $\mathrm{i}$ arbeidsmedisinsk epidemiologi, determinant (eksponering) og effekt (sykdom). Mens hele det medisinske fagområde har vært fokusert på å kvalitetssikre effektvariablen, har eksponeringsvariablen tradisjonelt vært stemoderlig behandlet. Det er overraskende at så grove surrogatvariable som f.eks. yrkestitler og tilhørighet til bransje så lenge og i så stor grad har fått råde grunnen. Årsaken til dette er selvsagt at slike data har vært lett tilgjengelige, og at slike «proxy» variable tross alt har avspeilet sterke gradienter i sykelighet. Ett hovedproblem er at disse gradienter bare delvis har sin bakgrunn i yrkeseksponering i mer snever forstand. En annen grunn til å kreve bedre kvalitet i eksponeringsbedømmelsen har sin bakgrunn i at surrogatdata og misklassifisering av eksponeringen maskerer sanne effekter. Når fokus endres fra eldre «høy risiko» eksponeringer som f.eks. nikkel og asbest, til lavrisiko eksponeringer, blir dette et betydelig problem. Tradisjonelle metoder basert på indirekte, kvalitative eksponeringsmål er derfor ikke lenger tilstrekkelig, verken for påvisning av årsaks-effekt sammenhenger eller for kvantitative formål for å etablere eksponering-respons sammenhenger.

Ideelt sett ville en best kunne sikre seg valide, kvantitative eksponeringsdata i prospektive undersøkelser. Men selv ved retrospektiv eksponeringskarak- terisering har det skjedd en betydelig utvikling innenfor den arbeidsmedisinske epidemiologien de senere år. Jobb-eksponeringsmatriser, yrkeshygienisk ekspertbedømmelse av retrospektive data, semikvantitative indekser basert på historiske eksponeringsmålinger, latenstidbetraktninger, bruk av tidsvinduer, og evt. farmakokinetiske modeller har vært benyttet $(21,22)$. Økende bruk av yrkeshygienikere i forbindelse med eksponeringsbedømmelse i epidemiologiske prosjekter har bidratt til økt kvalitet på slike studier (23).

Kun for et fåtall agens har en hatt mulighet til å benytte biologiske eksponeringsvariable, som f.eks. bly i blod og kvikksølv i urin. Men når interessant eksponerte kohorter, som f.eks. ansatte ved norske kloralkalifabrikker har vært overvåket med regelmessige undersøkelser av kvikksølv i urin i mer enn 40 år, kan dette benyttes som utgangspunkt for flere relevante eksponeringsmål, knyttet til eksponeringslengde, eksponeringsintensitet og kumulativ dose (24).

Det er også verdt å merke seg at en norsk forsker metodemessig har stått sentralt når det gjelder utvikling av eksponeringsbaserte dosebetraktninger. Overingeniør Jørgen Jahr ved Statens arbeidsmiljøinstitutt (den gang Yrkeshygienisk institutt) utviklet i 1974 en tidsvektet modell for doseberegning ved utvikling av silikose (25). Hans anliggende var at effekten av en kumulativ dose (kvarts) var tidsavhengig, der ansatte med kvartseksponering i ung alder utviklet silikose, mens samme kumulative eksponering i høy alder ikke ga silikose. Jahrs modell, med vekting av tid fra eksponering står som et sentralt bidrag til alternative epidemiologiske dosemodeller som kan benyttes (26).

\section{HVOR GÅR VI?}

Utviklingen for norsk arbeidsmedisinsk epidemiologi i årene som kommer vil for en stor del være betinget $i$ den endring som gradvis vil finne sted i næringslivet generelt. En forventet endring i eksponeringspanorama i norsk industri med færre eksponerte for tradisjonelle fysisk/kjemiske forurensninger på lavere nivåer, vil nødvendiggjøre en betydelig skjerpelse av våre epidemiologiske metoder, ikke minst når det gjelder eksponeringskarakterisering. Ved studier av arbeidsrelaterte sykdommer med lang utviklingstid, vil den epidemiologiske forskning fortsatt være noe «konservativ» $i$ sin natur, der vi i dag observerer helseeffekter av tidligere tiders eksponering. Dette gjelder f.eks. arbeidsbetinget kreft og lungesykdommer. Flere sannsynlige trender forventes likevel å være av betydning $\mathrm{i}$ den fremtidige arbeidsmedisinske epidemiologi.

\section{Okende gradienter}

Det er både nasjonalt og internasjonalt påvist store gradienter i helse, relatert til sosiale og økonomiske forhold. Det er nærliggende å anta at arbeidsmiljøet $\mathrm{i}$ mange tilfelle kan være en ikke uvesentlig determinant for disse forskjeller. Samtidig kan en få inntrykk av at 
det også er økende gradienter innenfor arbeidslivet med henblikk på eksponering for helseskadelige forhold, der småbedrifter og 1-2 manns bedrifter med lite fokus på arbeidsmiljø kan komme dårligere ut enn store bedrifter med et veletablert Helse-miljø-sikkerhetsarbeid. En mulig økende samvariasjon mellom dårlig arbeidsmiljø og forekomst av andre livsstilsrelaterte risikofaktorer vil også kunne bidra til økende helseforskjeller i Norge, noe som vil være en stor utfordring for videre forskning. Et problem i denne sammenheng er mindre tilgang på større, homogent eksponerte grupper. Det er ikke lett å foreta kvantitativ eksponeringsbedømmelse til epidemiologisk bruk i 1-2 manns bakgårdsbedrifter.

\section{Kompliserte årsaksnettverk}

Tradisjonelle, epidemiologiske undersøkelser innen det arbeidsmedisinske fagfelt har basert seg på relativt enkle årsaksrelasjoner, der et fåtall faktorer, gjerne knyttet til fysisk/kjemisk eksponering har vært gjenstand for systematisk kartlegging. Dette forventes gradvis å endre seg. Samvirke mellom arv og miljø, betydning av organisatorisk og psykologisk arbeidsmiljø, sosialt nettverk og livsstil vil i større grad komme i fokus i videre forskning. Det vil derfor bli nødvendig med bredt anlagte undersøkelser, basert på tverrfaglig kompetanse, og med utprøvning av nytt metodeverktøy. Årsakssøking og forebyggelsesstrategier må sannsynligvis søkes på forskjellig nivåer - der ikke bare individer, men også grupper/bedrifter kan betraktes som mulige observasjonsenheter («økoepidemiologi») (27).

Kartlegging av helseskade/helseeffekter forårsaket av kjemisk/fysiske faktorer forventes fortsatt å være et viktig felt innenfor arbeidsmedisinsk epidemiologi i mange år framover. Selv om det er holdepunkter for at færre personer vil bli relevant eksponert i fremtiden, er utviklingsmønsteret ikke entydig med hensyn til eksponeringsnivåer. Det er også klare eksempler på fortsatt høye eksponeringsnivåer i mange bransjer (28). Effekter av nye stoffer med ukjent toksikologi, og multikomponent, lavgradig eksponering vil også representere nye utfordringer i tillegg til etablerte problemstillinger. Diffust subjektivt ubehag knyttet til lavgradig kjemisk eksponering (multippel kjemisk hypersensitivitet) synes å kunne bli en økende arbeidsmedisinsk/miljømedisinsk utfordring. I større grad vil det også være nødvendig å se eksponering i indre og ytre miljø i sammenheng.

\section{Aktuelle helseeffekter}

En del av de «gamle» klassiske arbeidsmedisinske sykdommer er nå i ferd med å forsvinne (metallforgiftninger, støvlungesykdommer). Det forventes fortsatt oppmerksomhet rundt «tradisjonelle» helseeffekter som de siste 20 år har vært $\mathrm{i}$ fokus innefor arbeidsmedisinen (arbeidsbetinget kreft, nevrotoksisk skade (metaller, løsemidler), astma/lungesykdommer).
Arbeidsbetingete muskel/skjelettplager ventes i større grad å komme i fokus. I tillegg er det behov for økt forskning rettet mot en del «nyere» problemstillinger, som reproduksjonsskader, arbeidsrelatert hjerte/karsykdom, allergi/overfølsomhet samt irritanteffekter i hud og slimhinner.

Eksponering i arbeidslivet kan også tenkes å være utløsende faktorer for akutt helseskade, mer enn å være bakenforliggende årsaker. I hvilken grad kan f.eks. tungt fysisk arbeid, tunge løft eller liknende være utløsende faktorer for f.eks. hjerteinfarkt eller akutt rygg? Denne type problemstillinger har vært lite studert i arbeidsmedisinsk epidemiologi. Bruk av en case-crossover design, der basis eksponeringsfrekvens hentes fra hver persons tidligere eksponeringshistorie, som sammenliknes med tilsvarende eksponeringsfrekvens i tiden umiddelbart før en akutt hendelse, kan i denne sammenheng være en attraktiv design (29). En slik design har mye til felles med et crossovereksperiment, bortsett fra at den enkelte deltakeren (og ikke undersøkeren) velger periodene for eksponering og ikke-eksponering, og at eksponeringen fastsettes retrospektivt. En metodemessig fordel med en slik tilnærming er manglende interindividuell confounding (30). Arbeidsrelaterte ulykker, som til nå nesten ikke har vært gjenstand for epidemiologisk tilnærming, er også et aktuelt område for en slik design.

\section{Nye effektmarkorer}

Tradisjonelle endepunkter for arbeidsmedisinsk epidemiologi har vært manifest sykdom, evt. død. Med økende mulighet for påvisning av biomarkører, som evt. kan predikere senere utvikling av sykdom, kan mye av fokus innenfor dette feltet bli forskjøvet, der analyse av tidlige effektmarkører vil overta, eller i alle fall supplere bruk av tradisjonell sykdom som effektmarkører. Utvurdering av aktuelle biomarkører i epidemiologiske undersøkelser sammenholdt med alternative endepunkter bedømmes å bli sentrale felt for fremtidig arbeidsmedisinsk epidemiologisk forskning, noe som også vil kunne bidra til økt mekanismeforståelse. Bl.a. hormonelle og immunologiske faktorer vil i denne sammenheng være av interesse.

\section{Molekylaer epidemiologi}

Nyvinninger innefor molekylærbiologien de siste par tiår representerer også en utfordring for epidemiologien, ikke minst innenfor det arbeidsmedisinske fagfelt. Følgende tre aspekter synes spesielt interessante: Måling av addukter, genetisk bestemt metabolsk polymorfisme og susceptibilitet, og endring i onkogen/ supressor-gen aktivitet. Hvert av disse områder representerer klare utfordringer til valg av epidemiologisk design (31). Et problem med bruk av addukter er livslengde på de studerte celler (lymfocyter, hemoglobin i røde blodlegemer), der måling av adduktnivå kun avspeiler nylig eksponering. Blodprøvetaking noen måneder etter relevant eksponering for akrylamid blant 
tunnelarbeidere i Romeriksporten vil f.eks. kunne føre til påvisning av for lave verdier av akrylamidaddukter til hemoglobin enn under pågående eksponering. En tverrsnittsdesign synes derfor være en forutsetning for en slik tilnærming. Genetisk polymorfisme, som er en stabil egenskap kan derimot studeres uavhengig av tid, kanskje spesielt gunstig med en case control design. Slik kartlegging kan gi oss mulighet til å identifisere nettopp de grupper som har økt følsomhet for utvikling av sykdom. Vi studerer for tiden mulig sammenheng mellom akrylamideksponering, nervesystemskade og genetisk polymorfisme for glutathion-S-transferase.

\section{Arbeidsepidemiologiens framtid - harddata eller mykporno?}

Endring av fokus fra dødelighet og kreft til syndromer og symptomer har ført til en stadig økende bruk av «bløte» endepunkter i arbeidsmedisinsk epidemiologi. Slike endepunkter kan være subjektivt rapporterte symptomer, symptomkompleks eller syndromer, isolerte sykdomstegn, biokjemiske markører, eller kliniske diagnoser av forskjellig slag. Hva skjer metodemessig når f.eks. seleksjon av indekspersoner til case control undersøkelser baserer seg på subjektive symptomer? Muskel-skjelett epidemiologien har f.eks. i stor grad vært basert på slike endepunkter. Ett fristende alternativ kan være bruk av «objektive» biomarkører som mulig sykdomsmarkør. Relevansen av slike markører er foreløpig uklar, kfr. bruk av trendy, ikke validerte kits for inflammasjonsmarkører som yrkesepidemiologiske endepunkter. Det er fortsatt mye ugjort når det gjelder standardisering og validering av slike endepunkter før de kan tas i allment, epidemiologisk bruk.

Den økende bruk av spørreskjemaer innen arbeidsmedisinen er også en metodemessig utfordring. Koblet mot valide, objektiviserbare eksponeringsdata er dette mindre problematisk. En beveger seg imidlertid på grensen til metodemessig mykporno når både eksponering og effekt baseres på subjektive data. Sammenkobling av egen vurdert oppfatning av arbeidseksponering med egen rapportert helse, som bl.a. har vært benyttet i enkelte inneklimaundersøkelser er metodemessig problematisk og bør unngås (32). Epidemiologisk tilnærming til kartlegging av organisatorisk og psykososialt arbeidsmiljø representerer i denne sammenheng en spesiell utfordring, der det fortsatt gjenstår en betydelig utvikling av relevant metodeverktøy. Hvilke problemstillinger som i denne sammenheng er forskbare, og i hvilken grad epidemiologiske metoder er aktuelle for slike problemstillinger, gjenstår å se (33).

\section{AVSLUTNing}

Denne oversikten over enkelte hovedtrekk i norsk arbeidsmedisinsk epidemiologi illustrerer at fagfeltet har vært i betydelig utvikling, og at utfordringene for fremtidig virksomhet er store. Tatt i betraktning de begrensete ressurser som er tilgjengelig for epidemiologisk forskning, er det viktig at initiering av fremtidige undersøkelser baserer seg på eksplisitte prioriteringer. Det finske arbeidsmiljøinstituttet har følgende anbefalinger for sin epidemiologiske forskning: Problemet skal være forskbart, vitenskapelig relevant og nytt, helserisikoen skal være alvorlig og/eller omfatte mange personer, problemet skal forventes å øke i omfang, kompetansen må være til stede, og utdanningseffekten av prosjektet skal være stor (34). I teorien skulle det ikke være vanskelig å gi sin tilslutning til dette. Det er derfor et spørsmål om vi i stedet for å gjenta tradisjonelle studier av godt dokumenterte sammenhenger, eller gjennomføre trivielle studier med dårlig design, i en del tilfelle heller skulle vurdere «sample size: zero», dvs. ingen undersøkelse i det hele tatt. Implementering av allerede etablert kunnskap kan i en del tilfelle være like aktuelt som mer forskning.

\section{REFERANSER}

1. Nicholson WJ. Research issues in occupational and environmental cancer. Arch Environ Health 1984; 39: 190-202.

2. Doll R. The causes of death among gas-workers with special reference to cancer of the lung. Br J Ind Med 1952; 9: 180 .

3. Case RAM, Hosker ME, McDonald DB, Pearson JT. Tumours of the urinary bladder in workmen engaged in the manufacture of certain dyestuff intermediates in the British chemical industry. Part 1. Br J Ind Med 1954; 11: 75 .

4. Natvig H, Thiis-Evensen E. Arbeidsmiljø og helse: Yrkeshygienens og bedriftshelsetjenestens frembrudd og utvikling i Norge. Norsk bedriftshelstjeneste 1983; 1: 1-333.

5. Elstad D, Holst PM, Evang K, Riddervold L, Waaler E, Popper E. Saudapneumonien fra et yrkeshygienisk standpunkt. Nord Med 1939: 1014.

6. Thiis-Evensen E. Kiselstøvundersøkelser og silikoseforhold i en norsk porselensfabrikk. Doktoravhandling, Tanum, 1941. 254s.

7. Wolff A. Asbestosis pulmonum. Nord Hyg Tidsskr 1940; 21: 1-48. 
8. Hilt B. Epidemiology of asbestos-related diseases in the county of Telemark, Norway. Den norske kreftforening, Oslo 1987. Doktoravhandling.

9. Mowe G. Malignant mesothelioma in Norway: epidemiological, aetiological and medico-legal aspects. Statens arbeidsmiljøinstitutt, Oslo 1986. Doktoravhandling.

10. Kjuus H, Langård S, Skjærven R. A case-referent study of lung cancer, occupational exposures and smoking. III. Etiologic fraction of occupational exposures. Scand J Work Environ Health 1986; 12: 210-215.

11. Kongerud J. Occupational exposure and asthma. An epidemiologic study of aluminium potroom workers. Norsk tidskr arbeidsmed 1991, suppl. 2: 1-192. Doktoravhandling.

12. Søyseth V. Bronchial responsiveness in workers and children exposed to pollutants from an aluminium smelter. Norsk Epidemiologi 1995; 5 (Suppl. 1). Doktoravhandling.

13. Irgens Å, Krüger K, Skorve AH, Irgens LM. Yrke og reproduksjonsutfall. En populasjonsbasert registerstudie, Norge 1970-1993. Yrkesmedisinsk avdeling, Haukeland sykehus og Medisinsk fødselsregister, Universitetet i Bergen 1996. Rapport.

14. Kristensen P. Perinatal health and cancer in farmers' offspring. Norsk Epidemiologi 1997; 7 (Suppl. 3). Doktoravhandling.

15. NIOSH: Musculoskeletal disorders and workplace factors. A critical review of epidemiologic evidence for work-related musculoskeletal disorders of the neck, upper extremity and low back. DHHS (NIOSH) Publication No. 97-141. National Institute for Occupational Safety and Health. Cincinnati 1998.

16. Miettinen OS. Theoretical Epidemiology. Principles of Occurrence Research in Medicine. New York: John Wiley \& Sons, 1985.

17. Hobbesland $\AA$, Kjuus H, Thelle D. Mortality from cardiovascular disease and sudden death in ferroalloy plants. Scand J Work Environ Health 1997; 23: 334-341.

18. Skogstad M, Thorsen E, Haldorsen T, Melbostad E, Tynes T, Westrum B. Divers' pulmonary function after open-sea bounce dives to 10 and 50 metres. Undersea Hyperbar Med 1996; 23: 71-75.

19. Aaraas A, Horgen G, Bjørset H-H, Ro O, Thoresen M. Musculoskeletal, visual and psychosocial stress in VDU operators before and after multidisciplinary ergonomic interventions. Appl Ergon 1998; 29: 335-354.

20. Norges forskningsråd. Helse i arbeidslivet. Prosjektsammendrag (foreløpig versjon) 1999.

21. Kauppinen TP. Assessment of exposure in occupational epidemiology. Scand J Work Environ Health 1994; 20 special issue: 19-29.

22. Checkoway H, Pearce N, Crawford-Brown DJ. Research methods in occupational epidemiology. Monographs in epidemiology and biostatistics, Vol. 13. Oxford 1989. Oxford University Press.

23. Svendsen K. Eksponeringskaraktersering i yrkesepidemiologiske undersøkelser. Tidsskr Nor Laegeforen 1998; 118: 4399-4401.

24. Ellingsen D, Mørland T, Andersen A, Kjuus H. Relation between exposure related indices and neurological and neurophysiological effect in workers previously exposed to mercury vapour. Br J Ind Med 1993; 50: 736744.

25. Jahr J. Dose-response basis for setting a quartz threshold limit value: a new simple formula for calculating «lifetime dose» of quartz. Arch Environ Health 1974; 29: 338-40.

26. Checkoway H, Pearce N, Hickey JL, Dement JM. Latency analysis in occupational epidemiology. Arch Environ Health 1990; 45: 95-100.

27. Susser M, Susser E. Choosing a future for epidemiology: II. From black box to Chinese boxes and ecoepidemiology. Am J Public Health 1996; 86: 674-677.

28. Bye E, Bakke JV, Grov TG. Kjemisk-fysiske forhold i arbeid av betydning for helse. Kunnskapsmangler og forskningsbehov. Statens arbeidsmiljøinstitutt 1998. HD-1095/98 FOU.

29. Maclure M. The case-crossover design: a method for studying transient effects on the risk of acute events. $A m$ J Epidemiol 1991; 133: 144-153.

30. Mittelman MA, Maclure M, Robins J. Control sampling strategies for case-crossover studies: An assessment of relative efficiency. Am J Epidemiol 1995; 142: 91-98.

31. Söderkvist $\AA$, Axelson O. On the use of molecular biology data in occupational and environmental epidemiology. J Occup Environ Health 1995; 37: 84-90.

32. Kristensen P. Bias from nondifferential but dependent misclassification of exposure and outcome. Epidemiology 1992; 3: 210-215.

33. Sørensen BAa, Rapmund A, Fuglerud KS, Hilsen AI, Grimsmo A. Psykologiske, organisatoriske og sosiale faktorer i arbeid av betydning for helse. Kunnskapsmangler og forskningsbehov. Arbeidsforskningsinstituttet 1998; AFI rapportserie nr. 8/98.

34. FIOH: Research Policy 1988-95. Helsinki: Finnish Institute of Occupational Health, 1988. 